\title{
KEJADIAN AFASIA PADA STROKE FASE AKUT DAN PERUBAHAN SINDROM AFASIA PASCASTROKE
}

\author{
THE OCCURRENCE AND EVOLUTION OF APHASIA SYNDROME WITHIN \\ ONE MONTH AFTER STROKE
}

Vania Angeline Bachtiar, * Paulus Anam Ong, ** Sobaryati, ** Uni Gamayani** Lisda Amalia, ** Siti Aminah ${ }^{* *}$

\begin{abstract}
Introduction: Aphasia is a barrier for the rehabilitation of patients with stroke. The examination of aphasia is not only for diagnostic purpose, but also for the patient remaining language proficiency information and for comprehensive stroke treatment.

Aims: To study the incidence rate of aphasia in acute ischemic stroke and the change of the aphasia syndrome one month after stroke.

Methods: A descriptive observational with cohort study on ischemic stroke patients in Neurology ward, Dr. Hasan Sadikin Hospital and other hospitals in Bandung between November 2017 and February 2018. Tes Afasia, Diagnosis, Informasi dan Rehabilitasi (TADIR, a tools for diagnostic and rehabilitation of aphasia for Indonesian) was used to diagnose aphasia initially and repeated one month after diagnosis.

Results: Aphasia was found in 24 out of 102 patients with acute ischemic stroke (23.5\%). Majority was male $(58.3 \%)$, the average age of the patients was $55.6 \pm 11,4$ years and 8.8 years of education. The most common type of stroke causing aphasia was cardioembolic (62.5\%). Based on the types, the most aphasia syndrome found in this study were global aphasia (58.3\%), followed by Broca aphasia (25\%). Twenty patients with aphasia were re-examined after one month and $40 \%$ patients experienced transformation into other type of aphasia syndrome. Between patients with global aphasia, 45.5\% transformed into Broca aphasia and 9\% into transcortical motor aphasia. Patients with Broca aphasia did not experience transformation, 50.0\% of Wernicke aphasia transformed into conductive aphasia, and one conductive aphasia patient transformed into anomic aphasia.
\end{abstract}

Discussion: The occurrence of aphasia in acute ischemic stroke is 23.5\%. Within one month after stroke, 40\% patients with aphasia have shown transformation from one type into other type of aphasia syndrome.

Keyword: Aphasia, language proficiency, stroke, TADIR

\section{ABSTRAK}

Pendahuluan: Afasia dapat menghambat rehabilitasi pasien stroke. Pemeriksaan afasia, tidak hanya untuk keperluan diagnosis, namun juga sebagai informasi kemampuan berbahasa pasien yang tersisa dan akan bermanfaat untuk tata laksana stroke yang komprehensif.

Tujuan: Mengetahui kejadian afasia pada stroke iskemik fase akut dan perubahannya pada satu bulan kemudian.

Metode: Penelitian deskriptif observasional dengan rancangan kohort terhadap pasien stroke iskemik yang dirawat di ruang rawat inap Neurologi RSUP Dr. Hasan Sadikin dan beberapa RS di Bandung dan sekitarnya pada bulan November 2017 sampai Februari 2018. Penilaian afasia menggunakan Tes Afasia, Diagnosis, Informasi, dan Rehabilitasi (TADIR) yang diulang pada satu bulan kemudian.

Hasil: Afasia ditemukan pada 24 dari 102 pasien stroke iskemik fase akut (23,5\%). Mayoritas subjek adalah laki-laki $(58,3 \%)$ dengan rerata usia 55,6 $\pm 11,4$ tahun dan rerata lama pendidikan 8,8 tahun. Penyebab afasia terbanyak adalah stroke kardioemboli (62,5\%). Sindrom afasia yang terbanyak ditemukan adalah afasia global (58,3\%) diikuti afasia Broca (25\%). Pemeriksaan ulang pada satu bulan pascastroke dilakukan terhadap 20 pasien afasia, dan didapatkan $40 \%$ mengalami perubahan sindrom. Sebanyak 45,5\% pasien afasia global berubah sindrom menjadi afasia Broca dan 9,0\% menjadi afasia transkortikal motorik. Afasia Broca tidak mengalami perubahan sindrom. Seorang pasien dengan sindrom afasia Wernike berubah menjadi afasia konduksi; dan satu pasien dengan sindrom afasia konduksi berubah menjadi afasia anomik.

Diskusi: Kejadian afasia pada stroke iskemik fase akut adalah 23,5\%. Satu bulan pascastroke, 40\% pasien afasia mengalami perubahan sindrom.

Kata kunci: Afasia, kemampuan berbahasa, stroke, TADIR

*Departemen Neurologi FK Universitas Padjadjaran, Bandung. Korespondensi: vania.a.bachtiar@gmail.com. 


\section{PENDAHULUAN}

Data Riset Kesehatan Dasar (RISKESDAS) tahun 2013, stroke menempati urutan pertama penyebab kematian dan disabilitas. ${ }^{1}$ Afasia merupakan salah satu disabilitas yang sering dialami pasien pascastroke. ${ }^{2-4}$ Afasia adalah terganggunya proses berbahasa yang timbul akibat disfungsi area otak, yang dapat berupa gangguan satu atau lebih modalitas berbahasa, yaitu kemampuan berbicara, pemahaman bahasa lisan, membaca dan/atau menulis. ${ }^{3}$ Area otak yang berperan dalam proses berbahasa berada di hemisfer dominan (kiri) yaitu korteks perisilvii. Area ini meliputi area Broca, Wernicke, girus supramarginalis, dan girus angularis, serta serabut asosiasinya. ${ }^{5}$

Penelitian menunjukkan angka kejadian afasia pada stroke yang cukup tinggi, yaitu $13-40 \% .^{6-8}$ Pemulihan afasia dapat terjadi secara bertahap dalam beberapa bulan pertama pascastroke. Menurut Watilla dkk pemulihan afasia sulit diprediksi karena banyak faktor yang memengaruhi proses pemulihan tersebut. $^{\text {? }}$

Saat ini sebagian besar upaya tata laksana pada stroke fase akut di rumah sakit di Bandung masih terbatas pada pemulihan kesadaran, kekuatan motorik, pencegahan komplikasi tirah baring lama, dan mobilisasi dini pasien. Tata laksana terhadap gangguan fungsi luhur, terutama afasia belum mendapat banyak perhatian. Beberapa penelitian di Indonesia mengenai afasia pascastroke hanya terbatas pada angka kejadian afasia. Penelitian ini mempelajari kejadian afasia pada stroke fase akut dan perubahan sindromnya setelah 1 bulan.

\section{TUJUAN}

Untuk menilai kejadian afasia pada stroke fase akut dan perubahan sindrom afasia satu bulan kemudian.

\section{METODE}

Penelitian deskriptif observasional dengan rancangan kohort terhadap pasien stroke iskemik yang dirawat di ruang rawat inap Neurologi RSUP Dr. Hasan Sadikin, RSUD Kota Bandung, RSAU dr. M. Salamun, dan RS Dustira Cimahi pada bulan November 2017 sampai Februari 2018.

Kriteria inklusi adalah pasien stroke iskemik fase akut (1-10 hari dari awitan) yang dibuktikan dengan CT scan kepala, kesadaran compos mentis, pendidikan minimal kelas $3 \mathrm{SD}$, dan setuju untuk mengikuti penelitian. Adapun kriteria eksklusi adalah pasien dengan gangguan penglihatan dan pendengaran, gangguan sistemik berat, dan penyakit jantung atau paru berat, serta riwayat afasia sebelumnya.

Diagnosis afasia berdasarkan pemeriksaan Tes Afasia untuk Diagnosis, Informasi, dan Rehabilitasi (TADIR). Subjek dengan afasia diperiksa TADIR ulang satu bulan berikutnya, baik di poliklinik ataupun di rumah. Pengolahan data menggunakan analisis univariat SPSS 23, hasil penelitian disajikan dalam bentuk tabel dan diagram.

Tes Afasia untuk Diagnosis, Informasi, dan Rehabilitasi merupakan satu-satunya tes yang telah dinormalisasi dan standarisasi di Indonesia pada tahun 1996. Tes ini terdiri dari 4 subtes, yaitu subtes bicara, pemahaman bahasa lisan, pemahaman bahasa tulis, dan menulis. Hasil pemeriksaan dikonversi ke skor norma. Skor norma bernilai 1 sampai 5 sesuai derajat keparahannya; 1) tidak mungkin dilakukan tes; 2) sangat terganggu; 3) terganggu; 4) sedikit terganggu; dan 5) normal. Berdasarkan skor tersebut, afasia dibedakan dalam delapan sindrom, yaitu afasia global, afasia Broca, afasia Wernicke, afasia konduksi, afasia transkortikal motorik, afasia transkortikal sensorik, afasia transkortikal campuran, dan afasia anomik (Gambar 1). ${ }^{9}$

\section{HASIL}

Didapatkan sebanyak 102 subjek (Tabel 1) dengan proporsi laki-laki hampir sama dengan perempuan $(52 \%$ vs $48 \%)$, rerata usia $55,7 \pm 10,6$ tahun dan rerata lama pendidikan 8,8 tahun. Jenis stroke terbanyak berupa small vessel disease $(56,9 \%)$ terletak di subkortikal (56,9\%). Sebanyak 23,5\% subjek mengalami afasia dengan karakteristik yang hampir sama dengan keseluruhan subjek, namun terutama akibat kardioemboli (62,5\%). Sindrom afasia terbanyak adalah afasia global (56,5\%), tanpa adanya jenis afasia transkortikal sensorik, transkortikal campuran, dan anomik (Tabel 2). Namun dari 24 subjek, 3 orang meninggal dan 1 orang tidak dapat dihubungi, sehingga hanya 20 subjek yang dapat diperiksa kembali setelah 1 bulan. 


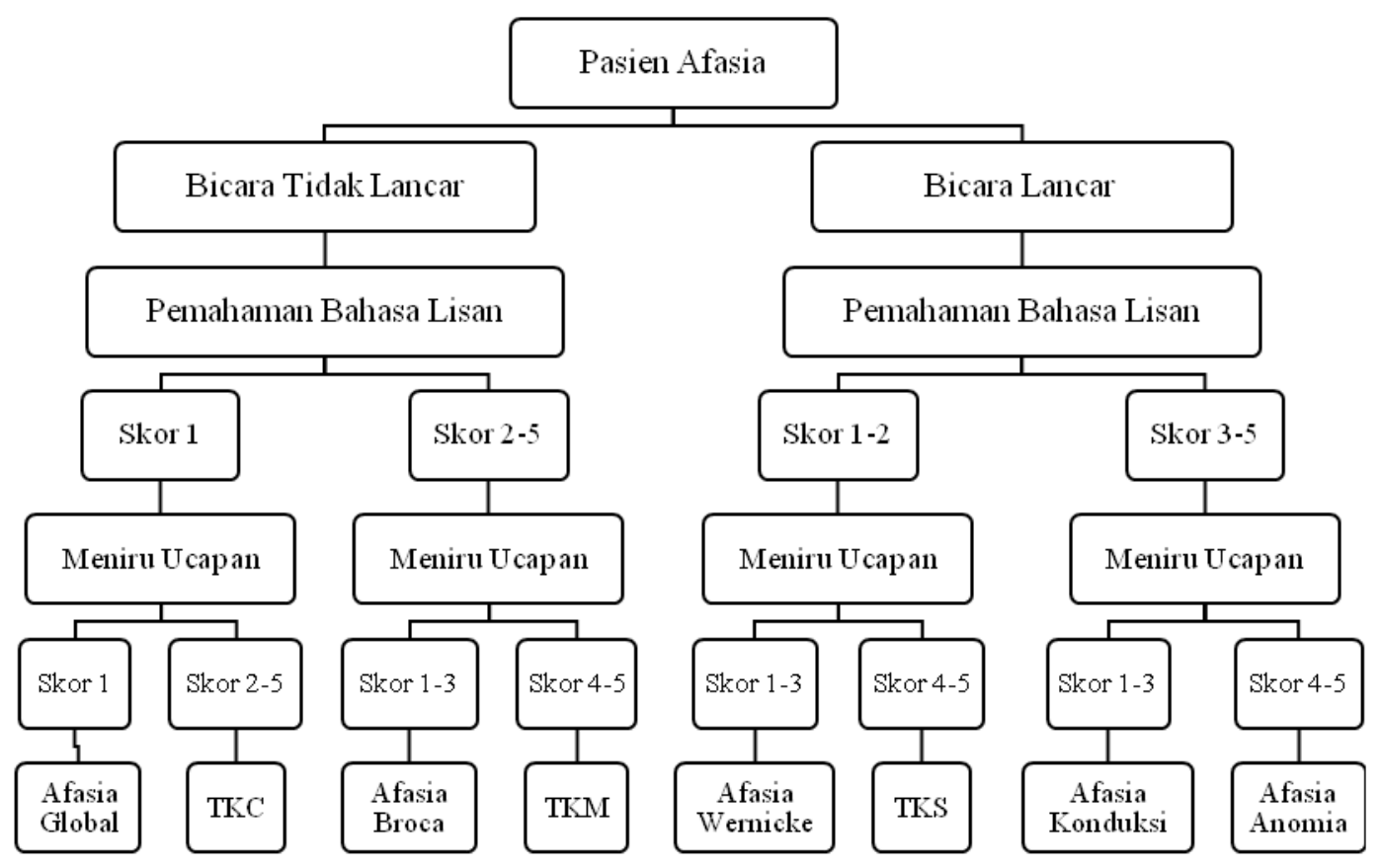

Gambar 1. Diagnosis Sindrom Afasia berdasarkan TADIR

TKC: Afasia Transkortikal Campuran; TKM: Afasia Transkortikal Motorik; TKS: Afasia Transkortikal Sensorik. ${ }^{9}$

Pada pemeriksaan TADIR kedua, didapatkan 8 dari 20 subjek (40\%) mengalami perubahan jenis sindrom afasia saat 1 bulan onset (Tabel 3). Perubahan tersebut terutama ditemukan pada subjek perempuan $(62,5 \%)$ dengan rerata usia 50,5 $\pm 10,5$ tahun dan memiliki rerata lama pendidikan yang lebih panjang $(9,3 \pm 4,1)$ tahun.

Sindrom afasia Broca yang ditemukan pada 6 subjek saat pemeriksaan awal, menjadi sebanyak 11 subjek pada pemeriksaan akhir. Sebaliknya sindrom afasia global yang awalnya terdapat pada 11 subjek, menjadi hanya pada 5 subjek (Tabel 4).
Tabel 5 memperlihatkan peningkatan norma TADIR yang terjadi pada seluruh pasien afasia 1 bulan pascastroke. Pada pemeriksaan awal (T1), sebagian besar subjek dengan afasia Broca memiliki nilai 1 (tidak dapat dinilai) yang kemudian menjadi hanya terganggu atau sedikit terganggu (nilai 3 atau 4) pada penilaian TADIR kedua (T2), di semua komponen penilaian. Pada subjek dengan afasia Wernicke, tidak banyak terjadi perubahan dari sebagian besar bernilai 1 dan 2 menjadi tetap 1 dan 2 pada T2. Demikian pula pada kelompok afasia konduksi, terjadi sedikit perbaikan dari mayoritas 3 menjadi 4 (T2). Adapun

\section{Tabel 1. Karakteristik Subjek}

\begin{tabular}{|c|c|c|c|}
\hline Karakteristik & $\begin{array}{l}\text { Afasia } \\
(n=24)\end{array}$ & $\begin{array}{l}\text { Tidak Afasia } \\
\quad(n=78)\end{array}$ & $\begin{array}{c}\text { Total } \\
(n=102)\end{array}$ \\
\hline \multicolumn{4}{|l|}{ Jenis kelamin } \\
\hline - Laki-laki (n, \%) & $14(58,3)$ & $39(50)$ & $53(52,0)$ \\
\hline - Perempuan (n, \%) & $10(41,7)$ & $39(50)$ & $49(48,0)$ \\
\hline Usia (rerata, tahun) & $55,6 \pm 11,4$ & $55,8 \pm 10,4$ & $55,7 \pm 10,6$ \\
\hline Pendidikan (rerata, tahun) & $8,4 \pm 3,7$ & $8,9 \pm 3,7$ & $8,8 \pm 3,7$ \\
\hline \multicolumn{4}{|l|}{ Stroke iskemik (TOAST) } \\
\hline - Large artery atherosclerosis $(\mathrm{n}, \%)$ & $9(37,5)$ & $10(12,8)$ & $19(18,6)$ \\
\hline - Kardioemboli (n, \%) & $15(62,5)$ & $10(12,8)$ & $25(24,5)$ \\
\hline - Small vessel disease (n, \%) & 0 & $58(74,4)$ & $58(56,9)$ \\
\hline
\end{tabular}

TOAST: Trial of ORG 10172 in Acute Stroke Treatment. 
Tabel 2. Distribusi Sindrom Afasia Awal (n=24)

\begin{tabular}{lc}
\hline \multicolumn{1}{c}{ Sindrom Afasia } & $\begin{array}{c}\text { Awal } \\
(\mathbf{n = 2 4 )}\end{array}$ \\
\hline Broca & $6(25)$ \\
Wernicke & $2(8,3)$ \\
Konduksi & $1(4,2)$ \\
Global & $14(58,3)$ \\
Transkortikal motorik & $1(4,2)$ \\
Anomik & 0 \\
\hline
\end{tabular}

Proporsi subjek dengan afasia kurang lebih sebanding antara laki-laki dan perempuan. Beberapa penelitian afasia menunjukkan tidak terdapat perbedaan insidens afasia antara jenis kelamin. ${ }^{6,13}$ Kardioemboli merupakan penyebab terbanyak afasia pada stroke iskemik dalam penelitian ini. Hal ini terjadi karena emboli otak yang bersumber dari jantung sering kali berukuran besar, sehingga dapat menyebabkan gejala stroke lebih berat. Sekitar empat perlima

Tabel 3. Karakteristik Subjek berdasarkan Perubahan Jenis Sindrom Afasia pada Pemeriksaan Akhir (n=20)

\begin{tabular}{lcc}
\hline \multicolumn{1}{c}{ Karakteristik } & $\begin{array}{c}\text { Berubah } \\
(\mathbf{n = 8 )}\end{array}$ & $\begin{array}{c}\text { Tidak berubah } \\
(\mathbf{n}=\mathbf{1 2})\end{array}$ \\
\hline Jenis kelamin & $3(37,5)$ & $9(75,0)$ \\
- Laki-laki (n, \%) & $5(62,5)$ & $3(25,0)$ \\
- Perempuan (n \%) & $50,5 \pm 10,5$ & $58,7 \pm 11,2$ \\
Rerata usia (tahun, SD) & $44,7 \pm 7,6$ & $60,33 \pm 11,4$ \\
- Laki-laki (tahun, SD) & $54 \pm 11$ & $53,7 \pm 11,0$ \\
- Perempuan (tahun, SD) & $7,3 \pm 1,9$ & $9,3 \pm 4,1$ \\
Rerata lama pendidikan & $7,7 \pm 1,5$ & $10,5 \pm 3,9$ \\
- Laki-laki (tahun, SD) & $7 \pm 2,2$ & $5,3 \pm 1,2$ \\
\hline
\end{tabular}

SD: standar deviasi.

subjek dengan afasia global terdapat penyebaran perbaikan dari mayoritas nilai 1 menjadi 1-4 pada T2.

\section{PEMBAHASAN}

Penelitian ini memperlihatkan distribusi jenis kelamin pada pasien stroke iskemik hampir sebanding antara laki-laki dan perempuan $(52 \%$ vs $48 \%$ ), dengan rerata usia 55,7 $\pm 10,6$ tahun. Hasil ini hampir sama dengan data stroke tahun 2015, bahwa insidens stroke pada perempuan dewasa muda dan pertengahan lebih rendah daripada laki-laki, namun meningkat pada usia $>55$ tahun. ${ }^{10} \mathrm{Hal}$ itu terjadi akibat adanya efek perlindungan dari hormon estrogen pada perempuan sebelum menopause. ${ }^{11}$

Rerata lama pendidikan yang dimiliki pasien stroke pada penelitian ini adalah 8,8 tahun. Pendidikan memiliki pengaruh terhadap luaran fungsional stroke yaitu semakin tinggi pendidikan formal yang dimiliki pasien, maka semakin baik luaran fungsional setelah stroke. ${ }^{12-13}$ Jun dkk mendapatkan kualitas hidup pasien pascastroke lebih rendah pada pasien yang hanya memiliki pendidikan sekolah dasar dan menengah dibandingkan mereka dengan pendidikan yang lebih tinggi. ${ }^{13}$ emboli dari jantung dapat memasuki sirkulasi darah otak anterior, sehingga dapat menyumbat pada arteri karotis interna, arteri serebri anterior, atau arteri serebri media. Arteri serebri media memperdarahi area kortikal dan subkortikal lobus frontal, temporal dan parietal. ${ }^{14}$

Kejadian afasia pada stroke iskemik fase akut dalam penelitian ini adalah $23,5 \%$. Hal ini sesuai dengan data dalam penelitian lain yang menunjukkan angka kejadian afasia pada stroke $13-40 \%{ }^{6-8}$ Sindrom afasia terbanyak pada stroke fase akut penelitian ini adalah afasia global diikuti afasia Broca. Bohra dkk pada tahun 2015 juga mendapatkan sindrom afasia terbanyak yaitu afasia global diikuti afasia Broca. ${ }^{6}$

Penelitian ini menunjukkan $40 \%$ subjek afasia mengalami perubahan sindrom dalam 1 bulan pascaawitan. Lebih dari setengah subjek dengan afasia global berubah menjadi afasia Broca dan transkortikal motorik. Satu pasien afasia Wernicke dan 1 pasien afasia konduksi juga memperlihatkan perubahan sindrom. Adapun seluruh pasien afasia Broca tidak memperlihatkan perubahan tipe sindrom. 
Tabel 4. Sebaran Sindrom Afasia Awal dan Akhir (n=20)

\begin{tabular}{|c|c|c|c|c|c|c|c|}
\hline \multirow[b]{2}{*}{$\begin{array}{c}\text { Sindrom Afasia } \\
\text { Awal }\end{array}$} & \multirow[b]{2}{*}{ (n) } & \multicolumn{6}{|c|}{ Sindrom Afasia Akhir } \\
\hline & & $\begin{array}{c}\text { Broca } \\
\text { (n) }\end{array}$ & $\begin{array}{l}\text { Wernicke } \\
\text { (n) }\end{array}$ & $\begin{array}{c}\text { Konduksi } \\
\text { (n) }\end{array}$ & $\begin{array}{c}\text { Global } \\
\text { (n) }\end{array}$ & $\begin{array}{c}\text { TKM } \\
\text { (n) }\end{array}$ & $\begin{array}{l}\text { Anomik } \\
\text { (n) }\end{array}$ \\
\hline Broca & 6 & 6 & - & - & - & - & - \\
\hline Wernicke & 2 & - & 1 & 1 & - & - & - \\
\hline Konduksi & 1 & - & - & - & - & - & 1 \\
\hline Global & 11 & 5 & - & - & 5 & 1 & - \\
\hline Total (Akhir) & & 11 & 1 & 1 & 5 & 1 & 1 \\
\hline
\end{tabular}

TKM: transkortikal motorik.

Perubahan sindrom yang terjadi dapat disebabkan karena usia rerata pasien yang lebih muda dibandingkan yang tidak mengalami perubahan sindrom. Hal ini dapat terjadi karena perubahan aliran darah otak dan perbedaan neurofisiologi yang menunjang fungsi berbahasa terkait proses penuaan. ${ }^{15-16}$ Aliran darah lebih turun pada area korteks otak di substansia alba, terutama di area prefrontal daripada area hemisfer otak lain. ${ }^{16-17}$

Perubahan lain yang terjadi pada usia tua adalah menurunnya masa otak, perubahan struktur saraf tanpa kematian sel, berkurangnya sinaps, dan disfungsi jaringan antarsaraf. ${ }^{16-17}$ Perbedaan lain, yaitu afasia pada usia muda sering mengenai lobus frontal dan disebabkan oleh kardioemboli, sedangkan pada usia tua di lobus temporal dan akibat proses aterosklerosis. ${ }^{7}$ Hal ini akan berpengaruh dengan sindrom afasia yang terjadi.

Sebagian besar subjek perempuan tampak mengalami perubahan sindrom. Hal ini dapat terjadi karena rerata lama pendidikan lebih tinggi yang dimiliki oleh subjek tersebut dibandingkan subjek perempuan lain yang tidak mengalami perubahan sindrom. ${ }^{12-13}$ Adapun tingkat pendidikan yang lebih tinggi dapat menjadi prediksi tingkat sosioekonomi yang lebih baik juga, sehingga akses ke pusat rehabilitasi dan kemampuan mendapatkan terapi adheren akan lebih mudah, serta pemahaman mengenai kesehatan kardiovaskular akan lebih baik. ${ }^{13}$

Semua pasien dengan perubahan sindrom mengalami pemulihan afasia. Selain itu, pasien yang tidak mengalami perubahan sindrom juga tetap menunjukkan pemulihan afasia satu bulan pascastroke. Hal ini berdasarkan peningkatan hasil pemeriksaan fungsi berbahasa yang diperoleh.
Pemulihan afasia ekspresif seperti afasia Broca terlihat sangat baik dalam penelitian ini, berbeda dengan potensi pemulihan afasia Wernicke, namun semua pasien tetap akan mengalami perbaikan. Hal ini dapat terjadi karena fungsi reseptif berbahasa pada afasia Broca tidak terganggu, sehingga mungkin akan membantu rehabilitasi pasien., ${ }^{3,18}$ Pemulihan pada area Broca yang terletak di lobus frontal juga disebabkan karena selain mendapat aliran darah dari arteri serebri media, area tersebut juga mendapat aliran darah dari cabang-cabang kortikal arteri kalosomarginal, dikenal juga sebagai arteri median dari korpus kalosum, yang merupakan cabang terbesar dari arteri perikalosal. ${ }^{19-20}$ Afasia global memperlihatkan perbaikan dalam pemahaman berbahasa (menjadi tipe tidak fasih), serupa dengan penelitian Bohra dkk. ${ }^{6}$

Satu bulan pascastroke didapatkan perbaikan nilai di setiap subtes berbahasa, namun belum mencapai nilai normal. Hal ini terjadi karena proses pemulihan berbahasa masih terus berlangsung hingga fase kronis stroke. Proses pemulihan berbahasa yang terjadi pada fase akut (beberapa minggu pertama) adalah akibat keberhasilan reperfusi jaringan yang telah mengalami iskemik dan atau hilangnya edema otak. ${ }^{21}$ Pemulihan pada fase selanjutnya terjadi karena resolusi dari diaskisis (berkurangnya metabolisme area normal yang jauh dari infark), serta proses pengalihan fungsi berbahasa secara utuh ke hemisfer kanan dan atau fungsi berbahasa diambil alih oleh area sekitar lesi dan area berbahasa lainnya di hemisfer kiri. ${ }^{21-22}$

Pemulihan afasia yang terjadi pada penelitian ini terutama juga karena adanya pemberian stimulus wicara dan bahasa dari anggota keluarga pasien yang memahami afasia atau yang sebelumnya ber- 
Tabel 5. Distribusi Perubahan Norma TADIR pada Setiap Sindrom Afasia $(n=20)$

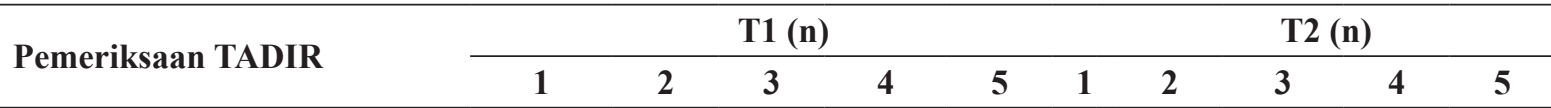

Afasia Broca ( $\mathrm{n}=6)$
Bicara (menamai-kata)
Bicara (menamai-kalimat)
Bicara (meniru ucapan)
Pemahaman bahasa lisan
Pemahaman bahasa tulis
Menulis

Afasia Wernicke ( $\mathrm{n}=2)$

Bicara (menamai-kata)

Bicara (menamai-kalimat)

Bicara (meniru ucapan)

Pemahaman bahasa lisan

Pemahaman bahasa tulis

Menulis

\begin{abstract}
Afasia konduksi ( $\mathrm{n}=1)$
Bicara (menamai-kata)

Bicara (menamai-kalimat)

Bicara (meniru ucapan)

Pemahaman bahasa lisan

Pemahaman bahasa tulis

Menulis
\end{abstract}

\begin{abstract}
Afasia Global $(\mathrm{n}=11)$
Bicara (menamai-kata)

Bicara (menamai-kalimat)

Bicara (meniru ucapan)

Pemahaman bahasa lisan

Pemahaman bahasa tulis

Menulis
\end{abstract}

\begin{tabular}{|c|c|c|c|c|c|c|c|c|}
\hline 3 & 2 & 1 & 0 & 0 & 0 & 1 & 1 & 4 \\
\hline 5 & 1 & 0 & 0 & 0 & 1 & 1 & 4 & 0 \\
\hline 3 & 1 & 2 & 0 & 0 & 0 & 2 & 4 & 0 \\
\hline 0 & 1 & 3 & 2 & 0 & 0 & 0 & 2 & 4 \\
\hline 3 & 0 & 3 & 0 & 0 & 0 & 0 & 5 & 1 \\
\hline 6 & 0 & 0 & 0 & 0 & 5 & 0 & 1 & 0 \\
\hline 2 & 0 & 0 & 0 & 0 & 1 & 1 & 0 & 0 \\
\hline 2 & 0 & 0 & 0 & 0 & 2 & 0 & 0 & 0 \\
\hline 1 & 1 & 0 & 0 & 0 & 1 & 1 & 0 & 0 \\
\hline 0 & 2 & 0 & 0 & 0 & 0 & 1 & 1 & 0 \\
\hline 2 & 0 & 0 & 0 & 0 & 1 & 1 & 0 & 0 \\
\hline 2 & 0 & 0 & 0 & 0 & 2 & 0 & 0 & 0 \\
\hline 0 & 0 & 1 & 0 & 0 & 0 & 0 & 0 & 1 \\
\hline 0 & 0 & 1 & 0 & 0 & 0 & 0 & 0 & 1 \\
\hline 0 & 0 & 1 & 0 & 0 & 0 & 0 & 0 & 1 \\
\hline 0 & 0 & 1 & 0 & 0 & 0 & 0 & 0 & 1 \\
\hline 0 & 0 & 0 & 0 & 1 & 0 & 0 & 0 & 0 \\
\hline 0 & 0 & 1 & 0 & 0 & 0 & 0 & 1 & 0 \\
\hline 11 & 0 & 0 & 0 & 0 & 8 & 2 & 1 & 0 \\
\hline 11 & 0 & 0 & 0 & 0 & 9 & 1 & 1 & 0 \\
\hline 11 & 0 & 0 & 0 & 0 & 7 & 2 & 1 & 1 \\
\hline 11 & 0 & 0 & 0 & 0 & 5 & 2 & 3 & 1 \\
\hline 11 & 0 & 0 & 0 & 0 & 8 & 1 & 1 & 1 \\
\hline 11 & 0 & 0 & 0 & 0 & 11 & 0 & 0 & 0 \\
\hline
\end{tabular}

TADIR: Tes Afasia, Diagnosis, Informasi dan Rehabilitasi; T1: Penilaian TADIR awal (fase akut); T2: Penilaian TADIR kedua (1 bulan pascastroke); Norma 1: tidak dapat dinilai, 2: sangat terganggu, 3: terganggu, 4: sedikit terganggu, 5: normal.

pengalaman merawat pasien afasia, dukungan dari lingkungan pasien, serta konsumsi obat-obatan yang rutin untuk mengatasi faktor risiko stroke dan mencegah stroke ulang.

Semua pasien penelitian belum mendapatkan rehabilitasi fungsi berbahasa yang terprogram di rumah sakit pada bulan pertama pascastroke karena keterbatasan jumlah dan kapasitas fasilitas yang ada, sehingga pasien mengalami kesulitan dalam akses ke lokasinya dan kesulitan mendapatkan jadwal rehabilitasi (menunggu antrian).
Keterbatasan penelitian ini yaitu tidak mempertimbangkan faktor-faktor yang dapat memengaruhi pemulihan afasia seperti usia, lama pendidikan, lingkungan dan keluarga, ukuran lesi, luas edema, perubahan lesi setelah 1 bulan pascastroke, dan terapi farmakologi maupun nonfarmakologi yang telah didapatkan pasien. Penelitian ini hanya menggunakan pemeriksaan penunjang CT scan kepala tanpa kontras sehingga tidak dapat menilai lokasi spesifik lesi pada stroke iskemik fase akut. Penelitian ini tidak multisenter sehingga data yang diperoleh tidak bervariasi dan tidak dapat mewakili populasi. 


\section{KESIMPULAN}

Kejadian afasia pada stroke iskemik fase akut adalah $23,5 \%$ dengan sindrom terbanyak adalah afasia global. Perubahan sindrom terjadi pada $40 \%$ pasien afasia dalam waktu 1 bulan pascastroke.

\section{DAFTAR PUSTAKA}

1. Kementrian Kesehatan Republik Indonesia. Profil kesehatan Indonesia tahun 2013. Jakarta: Kementrian Kesehatan Republik Indonesia; 2014. h. 161-2.

2. Hoffmann M, Chen R. The spectrum of aphasia subtypes and etiology in subacute stroke. J Stroke Cerebrovasc Dis. 2013;22(8):1385-92.

3. Webb WG. Adult disorders of language. Dalam: Neurology of the speech-language pathologist. Missouri: Elsevier; 2017. h. 206-16.

4. Hallowell B. Aphasia and other acquired neurogenic language disorders: a guide for clinical excellence. San Diego: Plural Publishing; 2017. h. 67-74.

5. Mersulam M. Central language mechanism and learning. Dalam: Webb WG. Neurology of the speech-language pathologist. Edisi ke-6. Missouri: Elsevier; 2017. h. 181-203.

6. Bohra V, Khwaja GA, Jain S, Duggal A, Ghuge VV, Srivastava A. Clinicoanatomical correlation in stroke related aphasia. Ann Indian Acad Neurol. 2015;18(4):424-9.

7. Watila MM, Balarabe SA. Factors predicting poststroke aphasia recovery. J Neurol Sci. 2015;352(12):12-8.

8. Purnomo AM, Sengkey LS, Damopolii CA. Angka kejadian afasia pada stroke di Instalasi Rehabilitasi Medik RSUP Prof. Dr. R. D. Kandou Manado tahun 2015. Jurnal e-Clinic. 2016;4(2):1-6.

9. Dharmaperwira-Prins RII. TADIR: tes afasia untuk diagnosis, informasi, rehabilitasi. Jakarta: FK Universitas Indonesia; 2000. h. 27-30, 37-48.

10. Mozaffarian D, Benjamin EJ, Go AS, Arnett DK, Blaha MJ, Cushman M, dkk. Heart disease and stroke statistics-2015 update: A report from the American heart association. Circulation. 2015;131(4):e29-e322.
11. Koellhoffer EC, McCullough LD. The effects of estrogen in ischemic stroke. Transl Stroke Res. 2013;4(4):390-401.

12. Hillis AE, Tippett DC. Stroke recovery: surprising influences and residual consequences (review article). Hindawi Publishing Corporation. 2014:2014;378263.

13. Jun HJ, Kim KJ, Chun IA, Moon OK. The relationship between stroke patients' socio-economic conditions and their quality of life: the 2010 Korean community health survey. J Phys Ther Sci. 2015;27(3):781-4.

14. Caplan LR, Amarenco P. Brain embolism. Dalam: Caplan LR, editor. Caplan's stroke: a clinical approach. Edisi ke-5. United Kingdom: Cambridge University Press. 2016. h. 312-51.

15. Ellis C, Urban S. Age and aphasia: a review of presence, type, recovery and clinical outcomes. Top Stroke Rehabil. 2016;23(6):430-9.

16. Ropper AH, Samuels MA, Klein JP. The neurology of aging, chapter 29. Dalam: Ropper AH, Samuels MA, Klein JP, editor. Adams and Victor's principles of neurology. Edisi ke-10. New York: McGraw-Hill Education; 2014. h. 606-14.

17. Murman DL. The impact of age on cognition. Semin Hear. 2015;36(3):111-21.

18. Kirshner HS. Aphasia. Medscape [serial online]. 2018 [diunduh 2 Maret 2018]. Tersedia dari: Medscape.

19. Stinnett TJ, Zabel MK. Neuroanatomy, broca area. StatPearls [serial online]. 2018 [Update 27 Oktober 2018]. Tersedia dari: Treasure Island, StatPearls Publishing.

20. Fitzgerald MJT, Gruener G, Mtui E. Clinical Neuroanatomy and Neuroscience. Edisi ke-6. China: Saunders Elsevier; 2012. h. 55-9.

21. Jarso S, Li M, Faria A, Davis C, Leigh R, Sebastian $\mathrm{R}$, dkk. Distinct mechanisms and timing of language recovery after stroke. Cogn Neuropsychol. 2013;30(78):454-75.

22. Heiss WD. Contribution of neuro-imaging for prediction of functional recovery arter ischemic stroke. Cerebrovasc Dis. 2017;44:266-76. 